\title{
Human casein alpha s1 (CSN1S1) skews in vitro differentiation of monocytes towards macrophages
}

\author{
Stefan Vordenbäumen ${ }^{1 *}$, Achim Braukmann², Irina Altendorfer ${ }^{1}$, Ellen Bleck ${ }^{1}$, Joachim Jose ${ }^{2}$
} and Matthias Schneider ${ }^{1}$

\begin{abstract}
Background: The milk-derived protein human Casein alpha s1 (CSN1S1) has recently been detected in blood cells and was shown to possess proinflammatory properties. In the present study, we investigated the effect of CSN1S1 on the differentiation of monocytes.

Methods: Primary human monocytes were stimulated with recombinant CSN1S1 and compared to cells stimulated with GM-CSF/L-4 or M-CSF/IFNy. Morphological changes were assessed by microscopy and quantification of surface markers of differentiation by FACS analysis. Phagocytic activity of CSN1S1 stimulated cells was measured by quantification of zymosan labeled particle uptake. The role of mitogen activated protein kinases for CSN1S1-induced differentiation of monocytes and proinflammatory cytokine expression was assessed by supplementation of specific inhibitors.
\end{abstract}

Results: CSN1S1 at a concentration of $10 \mu \mathrm{g} / \mathrm{ml}$ resulted in morphological changes (irregular shape, pseudopodia) and aggregation of cells, comparable to changes observed in M-CSF/FNy differentiated macrophages. Surface marker expression was altered after $24 \mathrm{~h}$ with an upregulation of CD14 (mean 2.5 fold) and CD64 (1.9 fold) in CSN1S1 stimulated cells. CSN1S1 treated cells showed a characteristic surface marker pattern for macrophages after $120 \mathrm{~h}$ of incubation (CD14 high, CD64 $4^{\text {high }}, C D 83^{\text {low }}, C D 1 a^{\text {low }}$ ) comparable to changes observed in M-CSF/IFNy treated monocytes. Furthermore, phagocytic activity was increased 1.4 and 1.9 fold following stimulation with $10 \mu \mathrm{g} / \mathrm{ml}$ CSN1S1 after 24 and 48 h, respectively. Early GM-CSF, but not GM-CSF/LL-4 induced differentiation of monocytes towards dendritic cells (DC) was inhibited by addition of CSN1S1. Finally, CSN1S1 induced upregulation of CD14 was impeded by inhibition of ERK1/2, while inhibition of the mitogen activated protein kinases JNK and p38 did not influence cellular differentiation. However, JNK and p38 inhibitors impeded CSN1S1 induced secretion of the proinflammatory cytokines IL-1b or IL-6.

Conclusions: CSN1S1 skews in vitro differentiation of monocytes towards a macrophage-like phenotype. Data is accumulating that functions of CSN1S1 are beyond nutritional properties and include immunomodulatory effects.

Keywords: Macrophage, Inflammation, Interleukin-1, Interleukin-6, Milk, Differentiation

\section{Background}

Human milk contains numerous proteins with properties beyond nutritional function [1]. Caseins are a main protein constituent of human milk and casein fragments exert a number of biological effects including the modulation of leukocyte adhesion [2], chemotactic properties [3-6], and

\footnotetext{
* Correspondence: stefan.vordenbaeumen@med.uni-duesseldorf.de 'Heinrich-Heine-University Düsseldorf, Department of Rheumatology, Moorenstr. 5, 40225 Düsseldorf, Germany

Full list of author information is available at the end of the article
}

inhibition of cell growth $[7,8]$ for instance. More recently, a member of the casein family, casein alpha s1 (CSN1S1), was shown to be expressed outside the mammary gland: overexpression was noted in lymph nodes of encephalomyelitic mice and blood of multiple sclerosis patients [9]. Furthermore, independent studies reported overexpression of CSN1S1 in synovial tissue of patients with osteoarthritis and rheumatoid arthritis [10-12]. Consequently, a potential function of CSN1S1 was further characterized by the finding of proinflammatory

\section{Biomed Central}


effects on monocytic cells, like for instance increased expression of IL-1 $\beta$ [13]. Thus, the concept of CSN1S1 as a multifunctional protein with both nutritional and immunomodulatory functions is evolving. Initial events in many inflammatory conditions crucially involve macrophages [14]. Macrophages usually originate from monocytes that are produced in the bone marrow and reach target tissues via systemic circulation [15]. In the present study, we therefore investigated the effect of CSN1S1 on monocytes and possible effects on cellular differentiation in vitro.

\section{Methods}

\section{Blood donors and monocyte isolation}

Cells were isolated from $40-60 \mathrm{ml}$ peripheral blood of healthy donors, collected into EDTA tubes (BD Bioscience, Plymouth, UK) by magnetic cell sorting with beaded CD14 antibodies (Miltenyi Biotec, Bergisch Gladbach, Germany). The number of experiments is indicated in the figure legends. Donors had to be free of any medication including over-the-counter drugs, without record of any chronic illness, and currently free of any acute illness such as infections. Cells were seeded out at $1 \times 10^{6} / \mathrm{ml}$ except for Western Blotting for extracellular signal-regulated kinase (ERK) and c-jun N-terminal kinase (JNK) experiments, cells were seeded out at $3 \times 10^{6} / \mathrm{ml}$. The experiments were conducted with the understanding and the consent of each participant. The study was approved by the ethics committee of the medical faculty of Heinrich-Heine-University.

\section{Cell culture and stimulation experiments}

Monocytes were cultured in RPMI $1640+$ GlutaMAX $^{\mathrm{mm}}$ supplemented with $10 \%$ heat inactivated fetal bovine serum, $50 \mathrm{IU} / \mathrm{ml}$ penicillin, and $50 \mu \mathrm{g} / \mathrm{ml}$ streptomycin (Invitrogen, Karlsruhe, Germany). $30 \mu \mathrm{g} / \mathrm{ml}$ polymyxin (Sigma-Aldrich, Munich, Germany) was added to experiments to exclude any LPS effects (Sigma-Aldrich) [13], except for the assessment of cellular morphology of living cells, where $200 \mathrm{ng} / \mathrm{ml}$ LPS was added in a control experiment. Recombinant human casein alpha S1 (CSN1S1) (Calbiochem, Darmstadt, Germany) was added to cultured cells in indicated concentrations for 24 or $120 \mathrm{~h}$. The following compounds were used to induce in vitro differentiation of monocytes as control experiments: M-CSF (R\&D Systems, Wiesbaden, Germany) $50 \mathrm{ng} / \mathrm{ml}$, GM-CSF $50 \mathrm{ng} / \mathrm{ml}, \mathrm{IL}-420 \mathrm{ng} / \mathrm{ml}$, IFNy 10 ng/ml (all CellGenix, Freiburg, Germany). For inhibition of casein effects, 20 $\mu \mathrm{mol} / \mathrm{l}$ mouse anti human M-CSF antibody (R\&D Systems) or cell permeable inhibitors were added as described [13] (all from Calbiochem): briefly, p38 mitogen-activated protein kinase (MAPK)-inhibitor ML3403 was used at 400 nM, ERK 1/2-inhibitor PD98059 was used at $50 \mu \mathrm{M}$, JNKinhibitor (JNK-inhibitor II) was used at $20 \mu \mathrm{M}$. Viability of cells was assessed by 3-(4,5-dimethylthiazol-2-yl)-5(3-carboxymethoxyphenyl)-2-(4-sulfophenyl)-2H-tetrazolium- assay (Promega, Mannheim, Germany) according to the manufacturer's instructions.

\section{Phagocytosis assay}

Primary human monocytes were seeded out at $1 \times 10^{6} / \mathrm{ml}$ and stimulated for $24 \mathrm{~h}$ with $1 \mu \mathrm{g} / \mathrm{ml} \mathrm{CSN} 1 S 1$ in the presence of $30 \mu \mathrm{g} / \mathrm{ml}$ Px in order to exclude any LPS effects. The uptake of fluorescent labelled zymosan particles was assessed with the colorimetric Cytoselect Phagocytosis Assay (Cell Biolabs, San Diego, CA, USA) according to the manufacturer's instructions after 24 and $48 \mathrm{~h}$. As a control, cells were cultured in medium including Px only.

\section{Microscopy}

Living cells were photographed at a scale of 400× magnification with Nikon Eclipse TE300 and Nikon Digital Camera DXM 1200 (Nikon, Düsseldorf, Germany) or cells were cultured in chamber slides (Nunc, Rochester, NY, USA), MayGrünwald-Giemsa stained (Merck, Darmstadt, Germany) and photographed at a scale of 200 and $400 \times$ magnification with Axioskop 2 Plus (Zeiss, Jena, Germany) and Nikon Digital CameraDS-2Mv (Nikon).

\section{Flow cytometry}

Antibodies were purchased from BD Bioscience (CD14FITC, CD64-PE, CD83-FITC, CD1a-PE), R\&D (CD115$\mathrm{PE}$ ), and Biolegend (San Diego, CA, USA: CD116-FITC). After stimulation, cells were incubated with the above antibodies at optimized concentrations. For the assessment of CSN1S1 effects on DC differentiation, primary human monocytes were incubated with $50 \mathrm{ng} / \mathrm{ml}$ GMCSF or $50 \mathrm{ng} / \mathrm{ml}$ GM-CSF plus $20 \mathrm{ng} / \mathrm{ml} \mathrm{IL-4}$ in the absence or presence of $10 \mu \mathrm{g} / \mathrm{ml}$ CSN1S1. Surface-marker expression was analyzed with FACSort (BD Biosience). Depending on the mean fluorescence intensity, the expression of markers is defined as "low" at < 100 and as "high" at $>100$ [15].

\section{Polymerase-chain-reaction (PCR)}

RNA was isolated with Rneasy ${ }^{\odot}$ Mini Kit (Qiagen, Hilden, Germany), and reverse transcription was performed using QantiTect ${ }^{\oplus}$ Reverse Transcription Kit (Qiagen) according to the manufacturer's instructions. PCR with real time measurement of fluorescence was carried out on the StepOnePlus Real-time PCR system (Applied Biosystems, Foster City, CA, USA) with $0.3 \mu \mathrm{M}$ gene-specific, exonspanning primers for IL-1b [GenBank: NM_000576.2] (Fw: GGGCCTCAAGGAAAAGAATC, Rv: TTCTGCTTGAG AGGTGCTGA) in triplicates using Qantitect ${ }^{\bullet}$ SYBR Green PCR Kit (Qiagen). Results were relatively quantified using glyceraldehyde-3-phosphate dehydrogenase GAP DH [GenBank NM_002046.3] (Fw: CCAGCCGAGC CACATCGCTC, Rv: ATGAGCCCCAGCCTTCTCC $\mathrm{AT}$ ) as internal and reference RNA (Stratagene, La 
Jolla, CA, USA) as external standard according to the $-\Delta \Delta$ CT-method.

\section{Enzyme-linked immunosorbent assay}

Quantikine $^{\circ}$ Human M-CSF-, IL-6- and IL-1-ELISA (R\&D Systems) were applied for measuring proteins in the supernatants of cell cultures according to the manufacturer's instructions. Determinations were carried out in duplicates. Absorbance was measured at $450 \mathrm{~nm}$ using the Anthos 2001 ELISA reader (Anthos Mikrosysteme, Krefeld, Germany).

\section{Western blot}

Western blot was carried out as described before for detection of p38 [16], and JNK or ERK [17]. Briefly, after stimulating primary human monocytes for $24 \mathrm{~h}$ with 10 $\mu \mathrm{g} / \mathrm{ml} \mathrm{CSN1S1} \mathrm{total} \mathrm{cell} \mathrm{proteins} \mathrm{were} \mathrm{prepared} \mathrm{for} \mathrm{SDS-}$ PAGE on a $12.5 \%$ gel. Electroblotting was carried out onto a polyvinyldifluoride membrane (Porablot; MachereyNagel, Düren, Germany). Membranes including the same samples were incubated with either p38-MAP kinase antibody (GeneTex, Eching, Germany) or phosphorylated p38-MAP kinase antibody, JNK or phosphorylated JNK antibody, and ERK or phosphorylated ERK antibody (all Antibodies-online, Aachen, Germany) at optimized concentrations over night at $4^{\circ} \mathrm{C}$. After appropriate washing procedures, the membranes were incubated with a 1:10,000 dilution of horseradish peroxidase (HRP)-conjugated anti-rabbit IgG (Sigma). Proteins were visualized via enhanced chemiluminescence (ECL) substrate (Santa Cruz Biotechnology, Santa Cruz, California) and detection by CCD camera (Intas Chemilux ECL Imager).

\section{Data presentation}

Data is presented as error-bars representing mean and standard deviation, representative FACS histograms, or representative photographs of microscopy slides and immunoblots. Data comparison was carried out by two-sided T-test with Bonferroni correction for multiple testing for comparison of surface markers after stimulation with CSN1S1 only, or by one way ANOVA with Bonferroni correction for multiple testing in experiments with inhibitors, antibodies, or when CSN1S1 stimulation was compared to GM-CSF/IL4 or M-CSF/IFN $\gamma$ stimulation. $\mathrm{P}<.05$ was considered significant.

\section{Results}

\section{CSN1S1 alters the morphology of monocytes}

After incubation of primary human monocytes with recombinant CSN1S1, changes in cellular morphology were noted. Living cells became adherent to the cell culture dish when incubated for $24 \mathrm{~h}$ with $1 \mu \mathrm{g} / \mathrm{ml}$ CSN1S1 and the development of pseudopodia was noted in some of the cells when stimulated with higher concentrations (Figure 1). These effects were not observed in the control cultures without CSN1S1, or in case lower concentrations of CSN1S1 $(1 \mathrm{ng} / \mathrm{ml}$ or $100 \mathrm{ng} / \mathrm{ml}$ ) were used (data not shown). For comparison, primary human monocytes were incubated with up to $200 \mathrm{ng} / \mathrm{ml}$ LPS, which had no visible effect on cellular morphology (Figure 1).

For a better characterization of cellular morphology, primary cells were cultured in chamber slides and stained. Morphology of living cells suggested a differentiation towards DC or macrophages. Thus, we included primary cells stimulated with GM-CSF or GM-CSF/IL4, and MCSF or M-CSF/IFN $\gamma$ for comparison to CSN1S1, as the latter stimulants are known to mediate in vitro differentiation towards the respective cell types [18,19]. Although we observed rapid morphologic changes in CSN1S1 stimulated cells, in vitro differentiation of monocytes is commonly carried out over 5 days. Thus, cells were incubated with the stimulants for both, $24 \mathrm{~h}$ and $120 \mathrm{~h}$. As can be seen in Figure 2, after $24 \mathrm{~h}$, control cells were round with little cytoplasm. In contrast, GM-CSF and GM-CSF/IL-4 induced enlarged cytoplasm. M-CSF stimulated cells displayed a smaller increase in cytoplasm with respect to cells stimulated with GM-CSF or GM-CSF/IL4. Moreover, $\mathrm{M}$-CSF, and especially M-CSF/IFN $\gamma$ treated cells displayed pseudopodia, which were absent in control cells or cells treated with either GM-CSF or GM-CSF/IL4. Furthermore, cells stimulated with M-CSF/IFN $\gamma$ formed small aggregates. These modifications observed in M-CSF or $\mathrm{M}-\mathrm{CSF} / \mathrm{IFN} \gamma$ stimulated cells were similar to changes observed in cells stimulated with CSN1S1, which formed aggregates and developed pseudopodia. After $120 \mathrm{~h}$, many control cells became adherent and showed a greatly enlarged cytoplasm. This was also observed for GM-CSF and GM-CSF/IL-4 treated cells. Stimulation with MCSF caused the development of pseudopodia besides the occurrence of adherent cells with enlarged cytoplasm. The addition of IFN $\gamma$ to M-CSF again led to a strong tendency towards cellular aggregation and the development of pseudopodia. This was also true for cells incubated with CSN1S1.

\section{CSN1S1 alters cell-surface marker expression}

The cellular morphology of CSN1S1 stimulated cells suggested a differentiation, either into macrophages or into DC. Besides morphological changes, differentiated cells of each type can be distinguished by distinct surface marker expression $[18,19]$. Therefore, primary human monocytes were incubated for 24 or $120 \mathrm{~h}$ with recombinant CSN1S1 and expression of representative surface markers for differentiation of monocytes towards macrophages or DC were analyzed by flow cytometry after immunolabeling. After 24 h stimulation with $10 \mu \mathrm{g} / \mathrm{ml} \mathrm{CSN1S1}$, upregulations of 


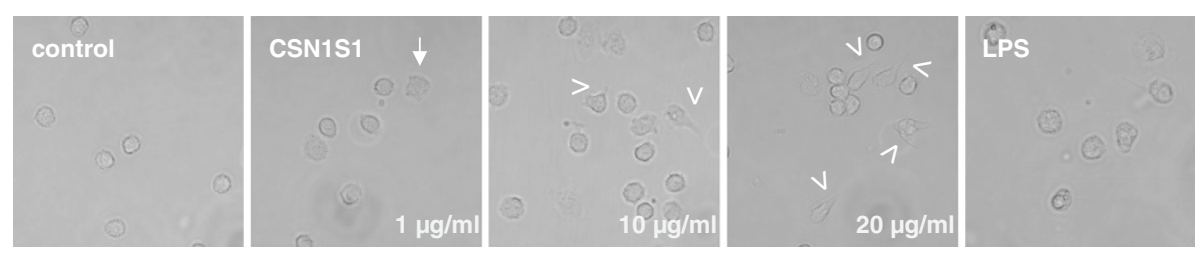

Figure 1 Live primary human monocytes stimulated with CSN1S1. Primary human monocytes were incubated with CSN1S1 for $24 \mathrm{~h}$ with increasing CSN1S1 concentrations in comparison to medium control and $200 \mathrm{ng} / \mathrm{ml}$ LPS. Living cells were photographed at 400x magnification. Cells developed irregular cytoplasm (arrow) and pseudopodia (arrow-head). Representative pictures of 10 experiments.

CD14 (2.5-fold \pm 1.0, SD) and CD64 (1.9-fold \pm 0.8$)$ were detectable (Figure 3a). Lower concentrations of CSN1S1 had no effect (data not shown). The pattern of surface markers obtained was characteristic for macrophages rather than for DC $\left(\mathrm{CD} 14^{\text {high }}, \mathrm{CD} 64^{\text {high }}, \mathrm{CD} 83^{\text {low, }} \mathrm{CD} 1 \mathrm{a}^{\text {low }}\right)$ $[15,18,19]$. After $120 \mathrm{~h}$ of incubation with CSN1S1, CD14 but not CD64 remained significantly upregulated. The pattern of surface markers remained the same $\left(\mathrm{CD} 14^{\text {high }}\right.$, $\mathrm{CD} 64^{\text {high }}, \mathrm{CD} 83^{\text {low, }} \mathrm{CD} 1 \mathrm{a}^{\text {low }}$ ) (Figure $\left.3 \mathrm{~b}\right)$. Next, we compared the surface markers of monocytes differentiated with CSN1S1 to in vitro differentiated monocytes towards macrophages (M-CSF/IFN $\gamma$ ) or DC (GM-CSF/IL-4). Such differentiation is known to be obtained by stimulation of

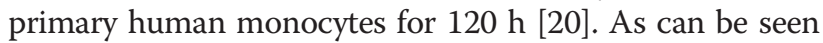
in Figure 3c, no difference in surface marker expression was observed after $24 \mathrm{~h}$. In contrast, after $120 \mathrm{~h}, \mathrm{CSN} 1 \mathrm{~S} 1$ and M-CSF/IFN $\gamma$ stimulation resulted in the same phenotype $\left(\mathrm{CD} 14^{\text {high }}, \mathrm{CD} 64^{\text {high }}, \mathrm{CD} 83^{\text {low, }} \mathrm{CD} 1 \mathrm{a}^{\text {low }}\right)$, while $\mathrm{GM}$ CSF/IL-4 caused a significant downregulation of CD14 and CD64 expression with upregulation of CD1a.

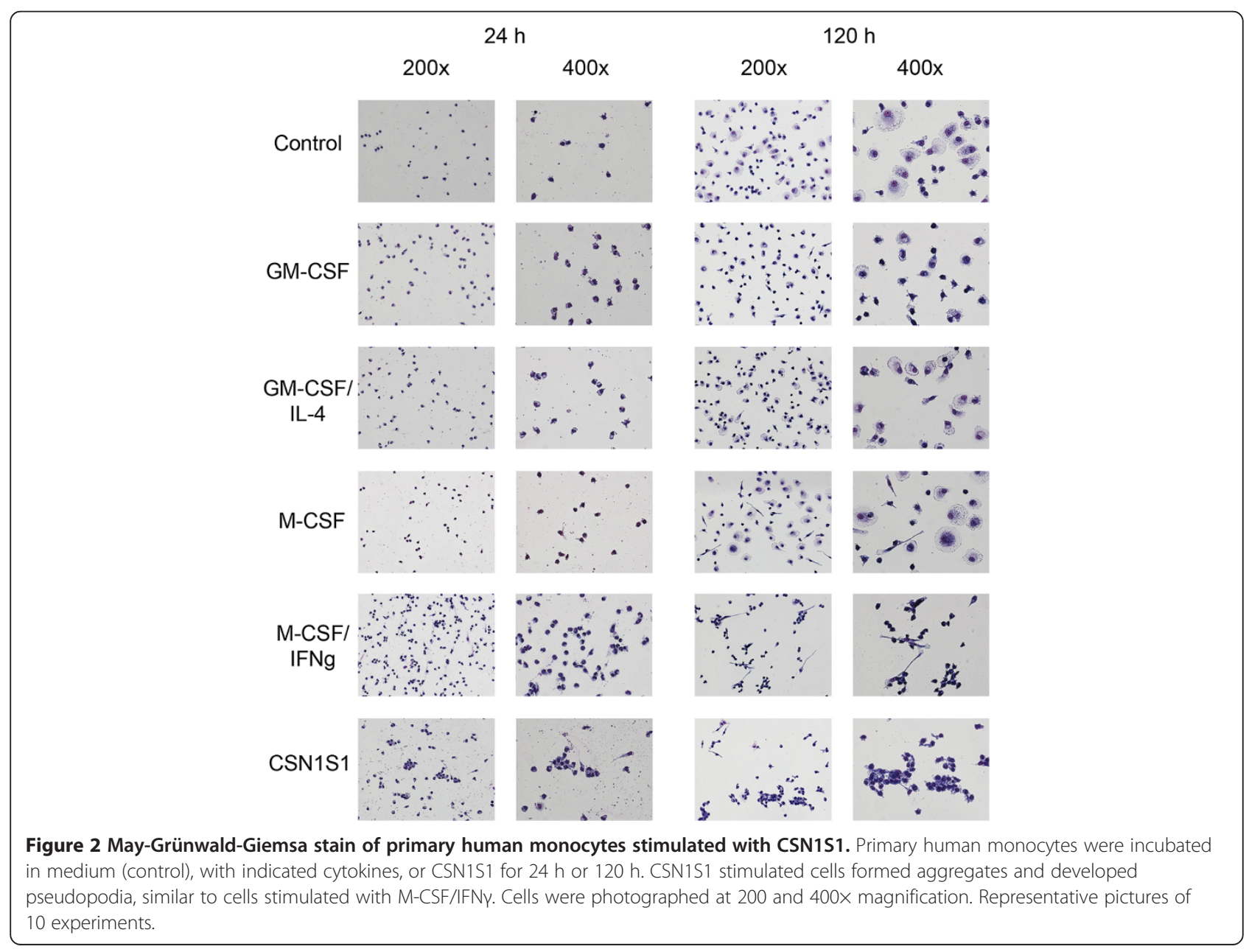


a

$24 \mathrm{~h}$

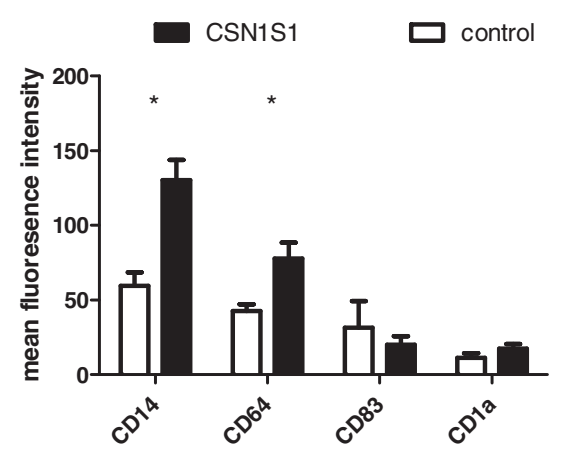

b

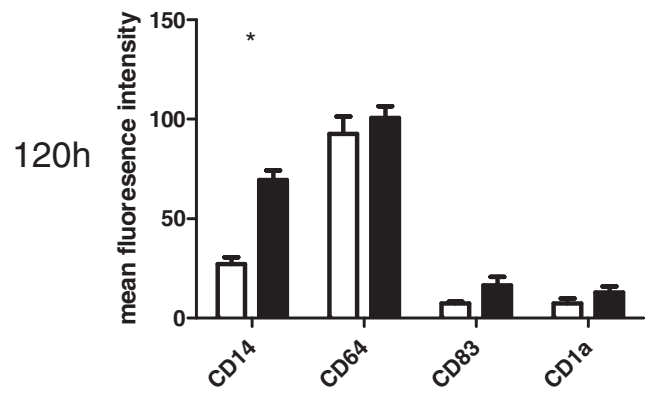

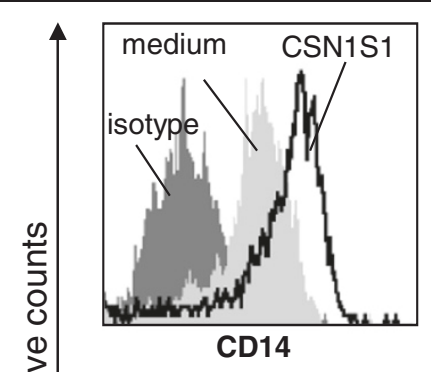
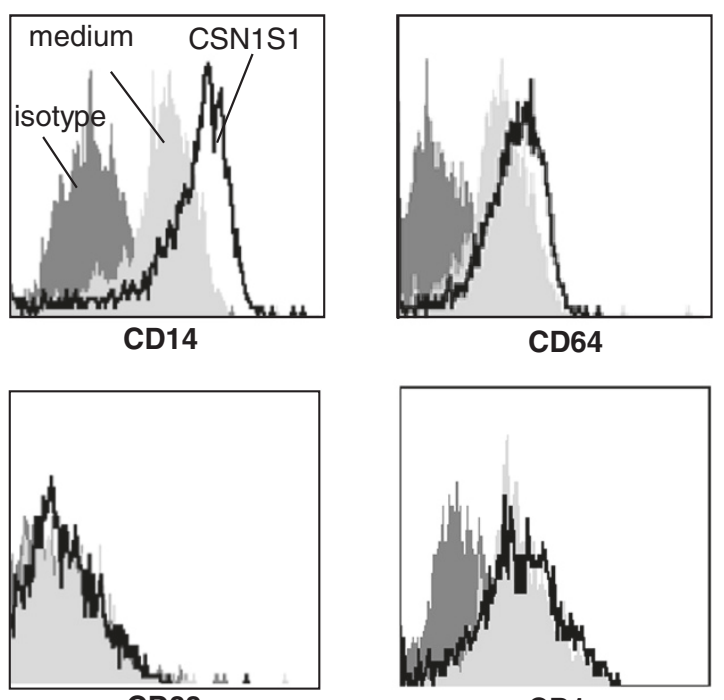

$$
\text { CD83 }
$$
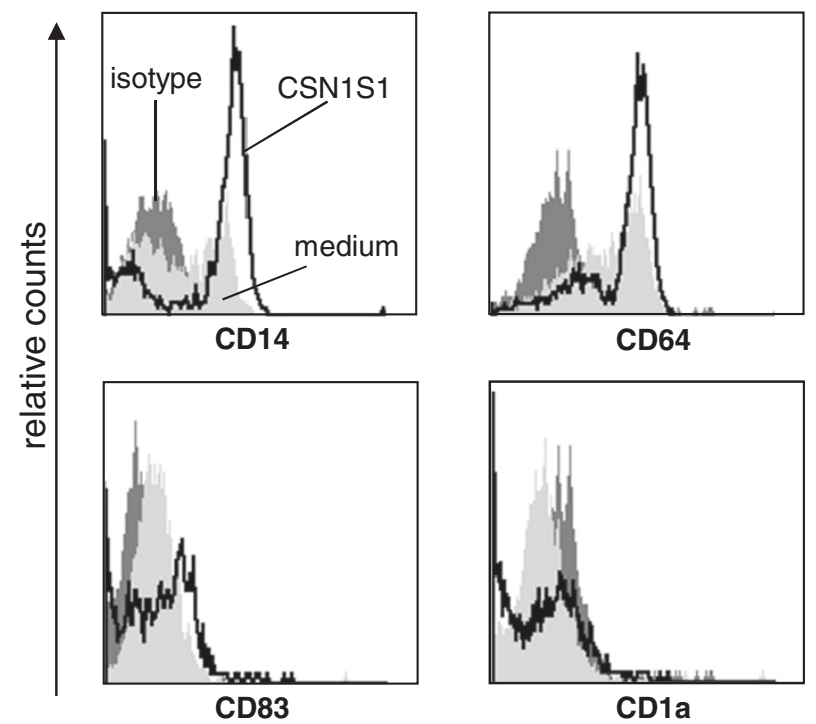

C
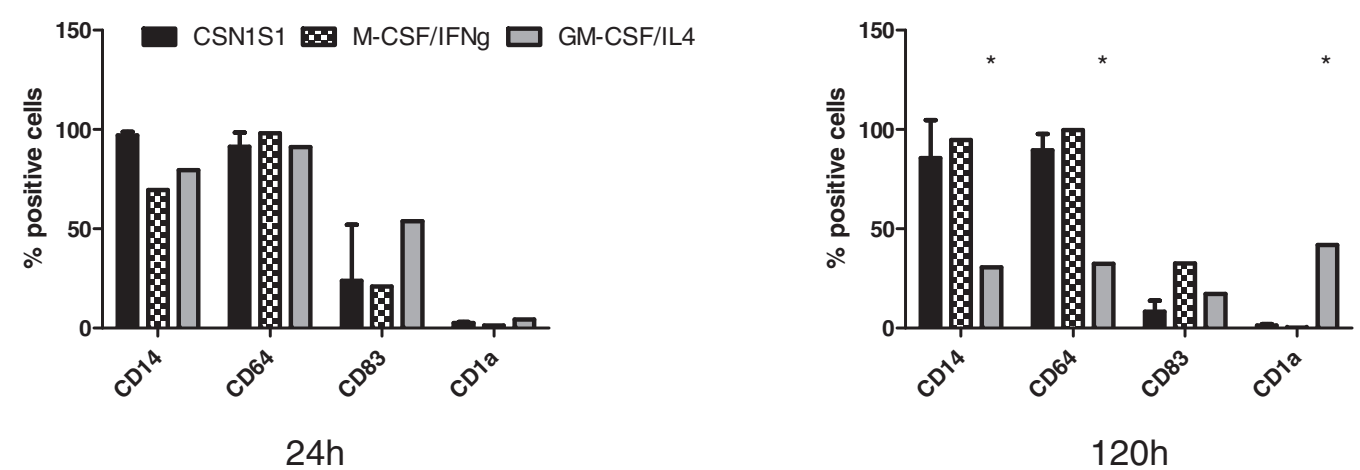

Figure 3 (See legend on next page.) 
Figure 3 FACS-Analysis of CSN1S1 stimulated cells. Surface markers of differentiation in CSN1S1 stimulated monocytes. $\mathbf{a}$, $\mathbf{b}$. Mean and SD of 6 experiments and representative flow cytometry data after 24 and $120 \mathrm{~h}$ of CSN1S1 stimulation or cells kept in medium only (control). * indicates $p<0.05$ according to two-sided t-test with Bonferroni correction for multiple testing. $\mathbf{c}$. Stimulation with CSN1S1 was compared to differentiation towards macrophages (M-CSF/IFNy) or dendritic cells (GM-CSF/IL-4) after 24 and $120 \mathrm{~h}$ (mean and SD of 6 experiments). * indicates $p<0.05$ according to ANOVA with Bonferroni correction for multiple testing.

\section{CSN1S1 increases phagocytic activity of monocytes}

Next, we assessed if incubation of primary human monocytes with CSN1S1 also results in functional changes. Increased phagocytic activity is a characteristic property of monocytes differentiated towards a macrophage-like phenotype $[18,19]$. Therefore, the intracellular uptake of labelled zymosan particles into primary human monocytes was assessed in a colorimetric assay after incubation with $10 \mu \mathrm{g} / \mathrm{ml}$ CSN1S1 for $24 \mathrm{~h}$. There was a marked increase in phagocytic activity of cells after $24 \mathrm{~h}$ (1.4-fold \pm 0.4 ), which was sustained after $48 \mathrm{~h}$ (1.9-fold \pm 0.5 , Figure $4 \mathrm{a})$.

\section{Influence of CSN1S1 on GM-CSF- and GM-CSF/IL-4- induced DC differentiation}

The above data suggested that CSN1S1 skews cellular differentiation of monocytes towards a macrophage-like phenotype. We were therefore interested, if an alternative route of differentiation, i.e. early differentiation of monocytes into DC, could be antagonized by the addition of $10 \mu \mathrm{g} / \mathrm{ml}$ CSN1S1 for $24 \mathrm{~h}$. For this purpose, primary human monocytes were incubated with GMCSF for $24 \mathrm{~h}$ in the presence or absence of CSN1S1 and the expression of cell surface markers was assessed by flow cytometry. As can be seen in Figure 4b, GM-CSF alone induced a characteristic immature DC cell surface marker pattern $\left(\mathrm{CD} 14^{\text {low }}, \mathrm{CD} 64^{\text {low }}, \mathrm{CD} 83^{\text {low }}, \mathrm{CD} 1 \mathrm{a}^{\text {high }}\right.$ ) [15]. The addition of CSN1S1 abolished GM-CSF effects and lead to a macrophage pattern $\left(C D 14^{\text {high }}, C D 64^{\text {high }}\right.$, CD83 $\left.{ }^{\text {low }}, C D 1 a^{\text {low }}\right)$. Besides GM-CSF, the combination of GM-CSF and IL-4 is a strong stimulus for in vitro DC generation [15]. Therefore, we additionally examined the properties of CSN1S1 in influencing GM-CSF/IL-4-induced DC differentiation. GM-CSF/IL-4 similarly caused characteristic immature DC cell surface marker expression $\left(\mathrm{CD} 14^{\text {low }}, \mathrm{CD} 64^{\text {low }}, \mathrm{CD} 83^{\text {low }}, \mathrm{CD} 1 \mathrm{a}^{\text {high }}\right)$ after $24 \mathrm{~h}$ of incubation, and this effect could not be inhibited by the addition of CSN1S1 (data not shown).

\section{The role of $\mathrm{M}-\mathrm{CSF}$ in CSN1S1-mediated cellular differentiation}

We previously reported that monocytic cells secrete GMCSF in response to CSN1S1 [13]. GM-CSF is known to influence the differentiation of monocytes towards a DC phenotype [21]. According to the present results, autocrine stimulation with CSN1S1 induced GM-CSF must therefore be overcome by alternative stimuli to allow for a differentiation towards the observed macrophage-like phenotype. We speculated that autocrine stimulation with M-CSF secreted upon CSN1S1 induction, upregulation of the M-CSF receptor CD115, or downregulation of the GM-CSF receptor CD116 could be responsible for the observed effects. First, primary human monocytes were stimulated with $10 \mu \mathrm{g} / \mathrm{ml} \mathrm{CSN1S1} \mathrm{for} 24 \mathrm{~h}$ and M-CSF secretion into supernatants was quantified by ELISA. As can be seen in Figure 4c, CSN1S1 increased the secretion of M-CSF into culture supernatants 29-fold. As a control, an M-CSF antibody was added to the experiments in order to demonstrate its capacity to bind all secreted M-CSF after stimulation (Figure $4 \mathrm{c}$ ). In the next step, differentiation of primary human monocytes was induced by $24 \mathrm{~h}$ incubation with $10 \mu \mathrm{g} / \mathrm{ml} \mathrm{CSN1S1}$ and the expression of CD14 and the M-CSF and GM-CSF receptors (CD115 and CD116, respectively) were determined by flow cytometry and immunolabeling (Figure 4d). CSN1S1 lead to the expected upregulation of CD14, while the expression of CD115 and CD116 remained unchanged. The addition of an M-CSF antibody to CSN1S1 stimulated primary human monocytes in the same concentration that was demonstrated to bind the secreted M-CSF protein (Figure 4c) did not alter the expression of CD14 or the receptors CD115 and CD116. Thus, neither changes in the expression of M-CSF, nor up- or downregulation of M-CSF receptor (CD115) or GM-CSF receptor (CD116) respectively, explained the preferential shift of monocyte differentiation towards macrophages in culture conditions that contain both $\mathrm{M}$ - and GM-CSF.

\section{CSN1S1 induced differentiation and cytokine expression may partially be mediated via MAPK}

We previously reported that CSN1S1 upregulates the expression and secretion of GM-CSF in monocytes in a p38 MAPK-dependent fashion [13]. We were therefore interested to analyze if cellular differentiation and the expression of other proinflammatory cytokines is also dependent upon MAPK pathways. In a first step, we analysed if addition of inhibitors of the MAPK pathways, i.e. JNK, p38, and ERK, influenced overall survival of primary human monocytes. As can be seen in Figure 5a, there was no significant effect on cellular vitality of monocytes by addition of inhibitors for $24 \mathrm{~h}$ in the concentrations used in subsequent experiments. Next, we assessed if the addition of these inhibitors was biologically effective in suppressing MAPK mediated signalling. LPS-signalling is known to be mediated via all three 


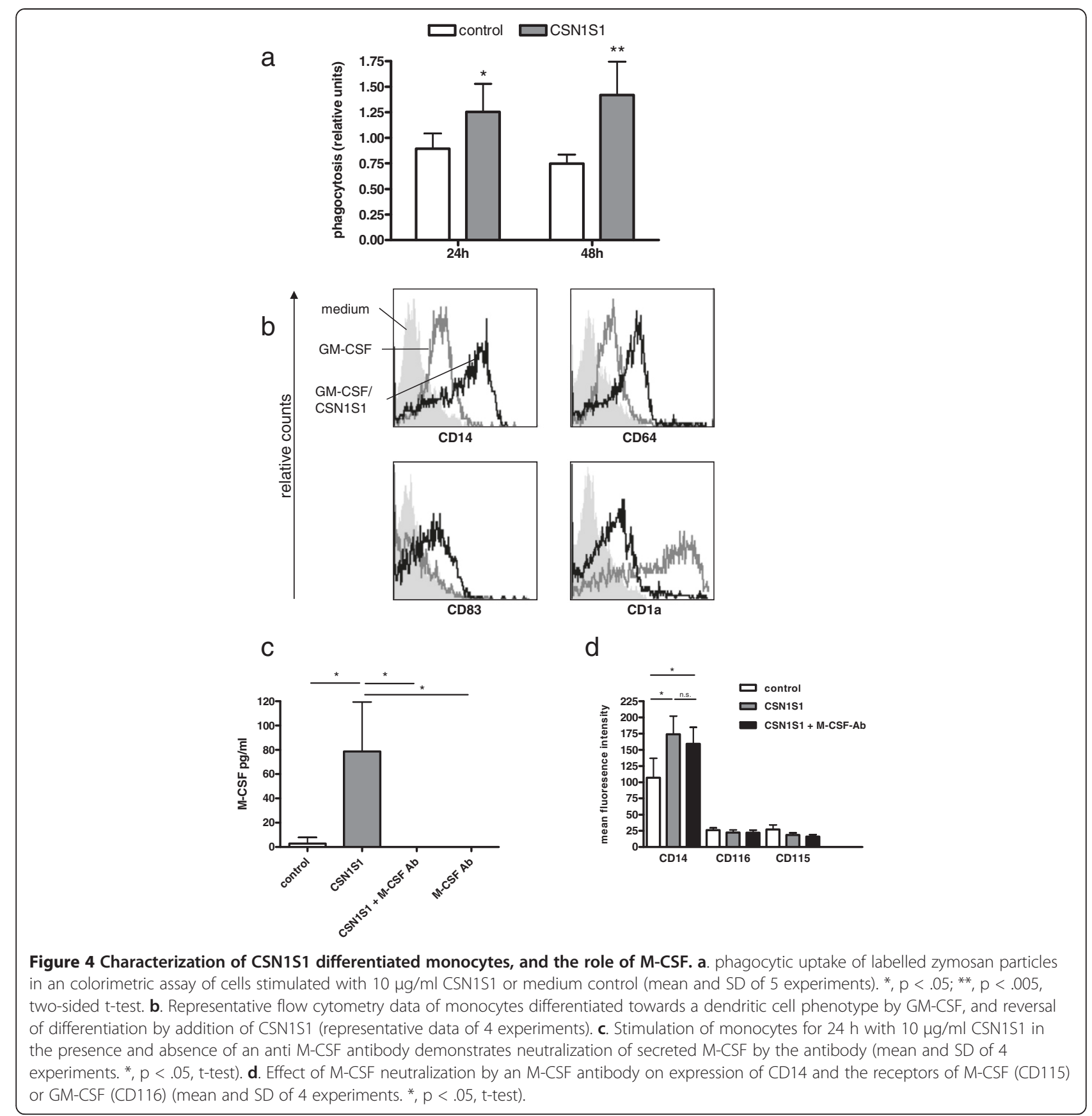

MAPK: JNK, p38, and ERK, and results in IL-1b expression [22]. Therefore, primary human monocytes were stimulated with LPS for $24 \mathrm{~h}$ in the presence and absence of MAPK inhibitors and IL-1b-mRNA expression was measured as a control experiment. As can be seen in Figure 5b, all inhibitors significantly suppressed IL1b-mRNA expression to a similar degree. In order to identify a putative signal transduction mechanism responsible for CSN1S1-induced cellular differentiation, we then tested the ability of MAPK inhibitors to impede the generation of a macrophage-like phenotype. Primary human monocytes were therefore incubated with MAPK inhibitors before stimulation with $10 \mu \mathrm{g} / \mathrm{ml} \mathrm{CSN1S1.} \mathrm{Cell}$ surface markers CD14 and CD64, upregulated during CSN1S1-induced differentiation as described above, were assessed by flow cytometry and immunolabeling. As depicted in Figure 5c, CSN1S1-mediated upregulation of CD14 was significantly decreased by inhibition of ERK, but not p38 and JNK. Next, we were interested to see if this effect was specific for CSN1S1 stimulated cells or if ERK-inhibition generally reduces CD14 expression in monocytes treated with M-CSF or GM-CSF. To this end, 
b

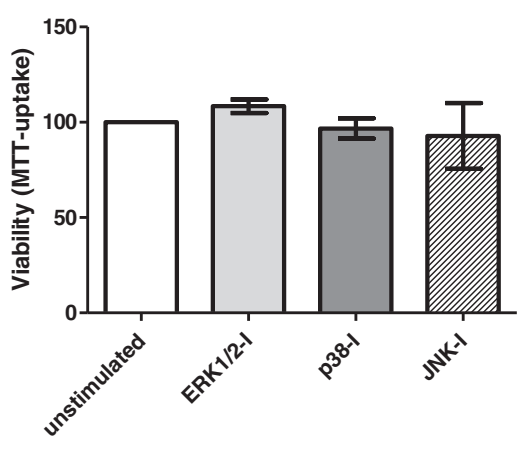

C

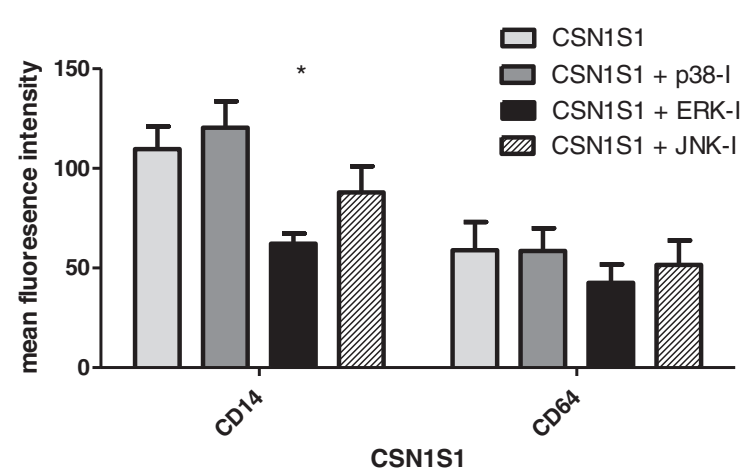

e

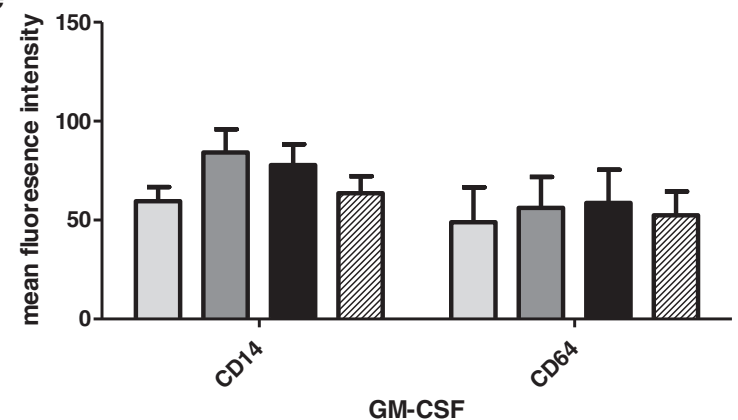

g

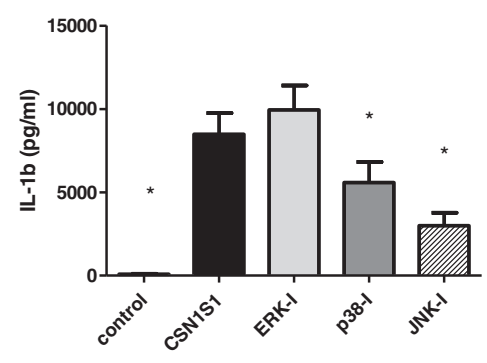

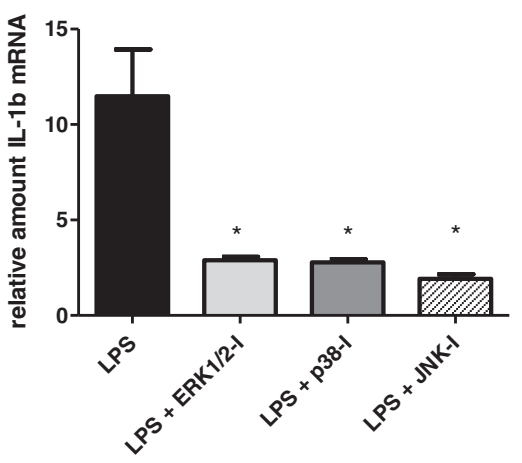

d

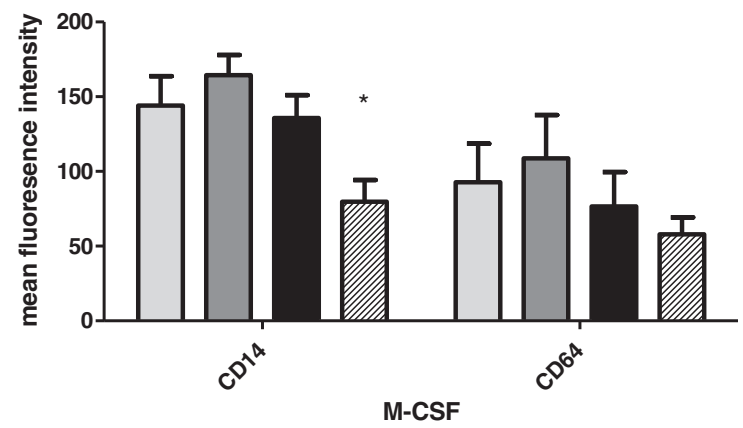

f
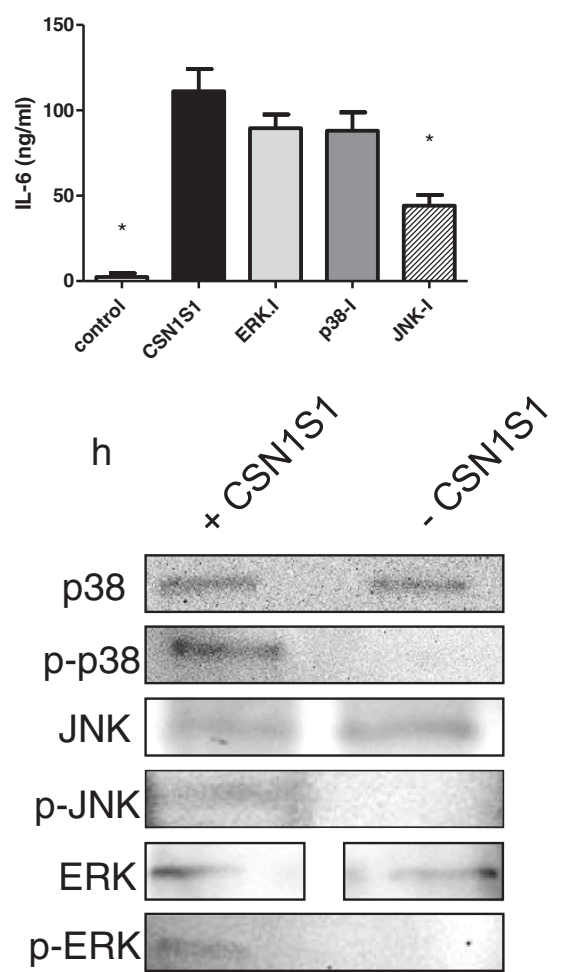

Figure $\mathbf{5}$ (See legend on next page.) 
(See figure on previous page.)

Figure 5 The role of MAPK in CSN1S1 induced cellular differentiation. a. Effect of ERK1/2-, p38-, and JNK-Inhibitor (I) on cellular viability of primary human monocytes. $\mathbf{b}$. Significant suppression of LPS-induced IL-1b-mRNA production by addition of ERK1/2-, p38-, and JNK-I (mean and SD of 4 experiments, $\mathrm{p}<0.05$, t-test). c-e. surface marker expression in primary human monocytes stimulated with $10 \mu \mathrm{g} / \mathrm{ml}$ CSN1S1 (c), M-CSF (d), and GM-CSF (e) for $24 \mathrm{~h}$ in the presence of indicated MAPK-I (mean and SD of 4 experiments. ${ }^{*} \mathrm{p}<0.05$, ANOVA with Bonferroni correction). $\mathbf{f}$. g. Secretion of IL-1b (f) and IL-6 (g) protein into supernatants of primary human monocytes stimulated with CSN1S1 and indicated MAPK-I (mean and SD of 4 experiments. ${ }^{*} p<0.05$, ANOVA with Bonferroni correction). $\mathbf{h}$. Western-blot of unphosphorylated and phosphorylated ( $p-$ ) p38-, JNK, and ERK-MAPK molecules in cell lysates of primary human monocytes stimulated for $24 \mathrm{~h}$ with $10 \mu \mathrm{g} / \mathrm{ml}$ CSN1S1. Images from P38 blots are separated, because protein samples were loaded in two pockets separated by an empty pocket due to blending of bands when adjacent pockets were used.

cells were treated with MAPK inhibitors prior to stimulation with M-CSF. As shown in Figure 5d, upregulations of CD14 in M-CSF treated cells were not influenced by inhibition of ERK as in CSN1S1 treated cells, but by inhibition of JNK. In contrast, MAPK inhibition did not influence surface marker expression in cells stimulated with GM-CSF for $24 \mathrm{~h}$ (Figure 5e). This suggests that signal transduction of CSN1S1-mediated differentiation is at least in part distinct from pathways used by M-CSF.

In order to evaluate whether CSN1S1 induces the expression of proinflammatory cytokines via the same route, primary human monocytes were stimulated with CSN1S1 and IL-1b and IL-6 protein-secretion into culture supernatants was measured in the presence and absence of MAPK inhibitors. As can be seen in Figure 5f-g, a significant reduction in the upregulation of IL-1b was noted with inhibition of p38 and JNK while IL-6 was decreased with inhibition of JNK only. Of note, inhibition of ERK did not reduce increased cytokine secretion in a significant manner.

The above results suggested that CSN1S1 engages all 3 MAPK molecules to either exert effects on cellular differentiation or proinflammatory cytokine expression. To confirm this notion, we additionally assessed activation, i.e. phosphorylation, of MAPK after incubation of primary human monocytes with $10 \mu \mathrm{g} / \mathrm{ml}$ CSN1S1 for $24 \mathrm{~h}$ by Western blot. As can be seen in Figure 5h, p38, JNK, and ERK were all phosphorylated when stimulated with CSN1S1, but not in control experiments without CSN1S1.

\section{Discussion}

In the present study, we demonstrate that exposure of primary human monocytes to CSN1S1 in vitro consistently skews cellular differentiation towards macrophages, including morphological changes, distinct surface marker expression, and functional properties such as increased phagocytic activity. Additionally, CSN1S1 induces the expression of proinflammatory cytokines [13]. Besides these functions, the most obvious role of human CSN1S1 is to provide an amino acid source to the new-born. However, the acquisition of additional functionality in an evolutionary context is an increasingly recognized phenomenon, also referred to as protein promiscuity $[23,24]$. In accordance with this notion, caseins are considered to have arisen from innate immune genes, and that their nutritive functions are a consequence of a more recent evolutionary development [25]. This assumption is based on the conserved organization of the casein genes in a cluster of innate immune genes that also includes the histatin/ statherin-family [25]. The hypothesis that CSN1S1 is a multifunctional protein is further supported by its state as a disordered protein with multiple potential tertiary conformations [26]. This last point has to be regarded with caution however, since - to the best of our knowledge crystallographic analyses of the human CSN1S1 structures currently do not exist. Since CSN1S1 is not only an endogenous produced protein, but is also a component of milk, the question arises, which potential functions CSN1S1-induced IL-1 $\beta$ expression could have in the offspring. Intestinal exposure to antigens and milk constitutes an important trigger for the development of a competent immune system in the new-born [27]. It is therefore interesting to speculate that CSN1S1 in mother milk may contribute to the development of a patent immune system by triggering immune responses to potential pathogens by activation of innate immune responses like for instance IL- $1 \beta$ secretion. Moreover, CSN1S1 by itself gives rise to sustained specific IgG antibody production in nursed individuals [28]. Early infantile autoantibody production in turn is speculated to confer protection to pathogens [29]. On the other hand, there are several mechanisms which could potentially prevent overwhelming inflammation triggered by exposure to CSN1S1 in milk: CSN1S1 is only a minor component of human milk and constitutes approximately $5 \%$ of the casein-fraction [30]. Moreover, CSN1S1 may be degraded by proteases in the healthy gut, thereby preventing IL-1 $\beta$ induction. Further research is clearly warranted to clarify these exciting new hypotheses and to explore, if variations in CSN1S1 exposure or extra-mammary expression may contribute to defective immune reactions. The recent findings of CSN1S1 overexpression in the autoimmune diseases multiple sclerosis and rheumatoid arthritis $[9,10,12]$ may be considered supportive of this hypothesis.

In the present experiments, the effect on all aspects of cellular differentiation, i.e. change of morphology, surface marker expression and increased phagocytosis, were observed rapidly, within $24 \mathrm{~h}$ of stimulation. Furthermore, CSN1S1 was able to reverse early GM-CSF-induced monocyte differentiation into $\mathrm{DC}$, resulting in a macrophage like 
phenotype. In vitro differentiation of monocytes towards macrophages or DC is most commonly carried out over 5 days, although more rapid differentiation in the course of several hours is recognized depending on the stimulus used [20]. In accordance with this notion, characteristic differences between in vitro differentiation towards macrophages (using M-CSF/IFNy) or DC (using GM-CSF/IL-4) were observed after 120 , but not $24 \mathrm{~h}$. Of note, surface markers were strikingly similar between M-CSF/IFNY and CSN1S1 treated cells. However, CSN1S1 failed to reverse in vitro generation of early DC by a combination of GMCSF and IL-4. This may be due to the more potent effect on in vitro DC generation by the combined cytokines compared to GM-CSF alone [15,21,31].

We were consequently interested to explore potential mechanisms employed by CSN1S1 to induce monocyte differentiation and cytokine expression. It was previously reported that primary human monocytes secrete GM-CSF in response to CSN1S1 [13]. This was somewhat puzzling, because GM-CSF is known to influence the differentiation of monocytes towards a DC phenotype [21]. On the other hand, according to the present data, CSN1S1 does also increase the secretion of M-CSF into culture supernatants. However, addition of a neutralizing M-CSF antibody to stimulated monocytes did not abrogate CSN1S1-effects. Importantly, there were also no changes in expression of the GM-CSF- or M-CSF-receptors (CD115 or CD116, respectively). Thus, CSN1S1 likely induces its effects on monocyte differentiation by a mechanism independent from M-CSF signalling. Concerning intracellular messengers, CSN1S1, like other proinflammatory cytokines such as IL-32 for example, employs p38 MAPK to induce proinflammatory cytokine expression [13,19]. Inhibition of another member of the MAPK family, ERK1/2, a wellknown regulator of cellular differentiation [32], but not p38 or JNK led to a decrease in CSN1S1 induced upregulation of CD14 in the present experiments. This effect may be specific for CSN1S1 rather than attributable to the process of differentiation of monocytes towards macrophages in general, because M-CSF induced upregulation of CD14 was inhibited by JNK exclusively. Furthermore, in contrast to differentiation, the secretion of proinflammatory cytokines (i.e. IL-6 and IL-1b) was influenced by the inhibition of JNK and/or p38, but not by ERK1/2. It cannot be excluded that other second messengers are employed for CSN1S1 induced cellular differentiation as well, especially because CD64 was not significantly affected by ERK1/2 inhibition. In conclusion, the data suggest that MAPK may be differentially involved in mediating CSN1S1 induced effects on cellular differentiation or cytokine expression. Further research in this direction is warranted however, before firm conclusions can be drawn.

A limitation to the study consists in the fact that the concentration of CSN1S1 in potentially relevant tissues for monocyte differentiation such as e.g. inflamed nerves, joints, or even the gastrointestinal tract is unknown. In order to simulate physiologic conditions, the concentrations of CSN1S1 used in the present experiments was determined based on previous observations: While in vitro-experiments suggest that ectopic CSN1S1 secretion by monocytes is in the range of $\mathrm{ng} / \mathrm{ml}[9,13]$, human milk contains $2.4 \mathrm{mg} / \mathrm{ml}$ total casein [33], approximately $5 \%$ of which is made up of CSN1S1 [30]. This results in a concentration of $120 \mu \mathrm{g} / \mathrm{ml}$ CSN1S1. Although proteins contained in milk are exposed to proteases within the digestive tract, they may be absorbed in an intact form which is even favoured by immature digestive functions of infants and protease inhibitors within milk [34]. Thus, concentrations used in the present experiments may reflect local conditions in vivo.

\section{Conclusions}

Human CSN1S1 influences the differentiation of monocytes towards macrophages in vitro and mediates the expression of proinflammatory cytokines. This process is at least partially dependent on differential MAPK signalling. The notion of CSN1S1 as a multifunctional protein with immunomodulatory properties beyond nutritional aspects is further evolving.

\section{Abbreviations}

CSN1S: Human casein alpha S1; GM-CSF: Granulocyte-macrophage colonystimulating factor; M-CSF: Macrophage colony-stimulating factor;

FACS: Fluorescence activated cell sorting; MAPK: Mitogen associated protein kinase; ERK1/2: Extracellular signal-regulated kinase 1/2; JNK: c-Jun N-terminal kinase; DC: Dendritic cells.

\section{Competing interests}

$S V, A B, I A, E B, J J, M S$ report no conflict of interests.

\section{Authors' contributions}

Conceived the study: SV, JJ, MS. Data acquisition: SV, AB, IA, EB. Data analysis and manuscript preparation: SV, JJ, MS. All authors read and approved the final manuscript.

\section{Acknowledgements}

The authors gratefully acknowledge financial support of this study by an unconditional grant from the "Hiller-Stiftung", Erkrath and from the

"Forschungskommission" of the Medical Faculty of Heinrich-Heine-University Düsseldorf.

\section{Author details}

'Heinrich-Heine-University Düsseldorf, Department of Rheumatology, Moorenstr. 5, 40225 Düsseldorf, Germany. ${ }^{2}$ Westfälische Wilhelms-University Münster, Institute of Pharmaceutical and Medicinal Chemistry, Correnstr. 48, 48149 Münster, Germany.

Received: 1 August 2013 Accepted: 30 September 2013 Published: 2 October 2013

\section{References}

1. Hvatum M, Kanerud L, Hällgren R, Brandtzaeg P: The gut-joint axis: cross reactive food antibodies in rheumatoid arthritis. Gut 2006, 55:1240-1247

2. Aihara K, Ishii H, Yoshida M: Casein-derived tripeptide, Val-Pro-Pro (VPP), modulates monocyte adhesion to vascular endothelium. J Arthroscler Thromb 2009, 16:594-603.

3. Katagiri T, Adachi I, Terao T, Osawa T: Alpha-casein-binding proteins of guinea pig macrophage membranes and their possible roles in chemotaxis. J Biochem 1980, 87:1421-1430. 
4. Lewis SL, van Epps DE: Demonstration of specific receptors for fluoresceinated casein on human neutrophils and monocytes using flow cytometry. Inflammation 1983, 7:363-375.

5. Solymossy M, Nagy Z, Tóth G, Antoni F: Interaction of casein with human polymophonuclear cells. Biochem Med Metab Biol 1986, 35:193-301.

6. van Epps DE, Bankhurst AD, Williams RCJ: Casein-mediated neutrophi chemotaxis. Inflammation 1977, 2:115-123.

7. Procoví C, Conesa C, Barbana C, Pérez MD, Calvo M, Sánchez L: Comparison of the activity of human and bovine milk on two cell lines. J Dairy Res 2009, 76:308-316.

8. Ramos-Mandujano G, Weiss-Steider B, Melo B, Córdova Y, Ledesma-Martínez E, Bustos S, Silvestre O, Aguiniga I, Sosa N, Martínez I, et al: Alpha-, betaand kappa-caseins inhibit the proliferation of the myeloid cell lines 32D $\mathrm{Cl} 3$ and WEHI-3 and exhibit different differentiation properties. Immunobiology 2008, 213:133-141.

9. Otaegui D, Mostafavi S, Bernard CCA, de Munain AL, Mousavi P, Oksenberg JR Baranzini SE: Increased transcriptional activity of milk-related genes following the active phase of experimental autoimmune encephalomyeltitis and multiple sclerosis. J Immunol 2007, 179:4074-4082.

10. Galligan CL, Baig E, Bykerk V, Keystone EC, Fish EN: Distinctive gene expression signatures in rheumatoid arthritis synovial tissue fibroblast cells: correlates with disease activity. Genes Immunity 2007, 8:480-491.

11. Karlsson C, Dehne T, Lindahl A, Brittberg M, Pruss A, Sittinger M, Ringe J: Genome-wide expression profiling reveals new candidate genes associated with osteoarthritis. Osteoarthritis Cartilage 2010, 18:581-592.

12. Ungethuem U, Haeupl T, Witt H, Koczan D, Krenn V, Huber H, von Helversen TM, Drungowski M, Seyfert C, Zacher J, et al: Molecular signature and nex candidates to target the pathogenesis of rheumatoid arthritis. Physiol Genomics 2010, 42:267-282.

13. Vordenbäumen $S$, Braukmann A, Petermann $K$, Scharf A, Bleck $E$, von Mikecz A, Jose J, Schneider M: Casein alpha s1 (CSN1S1) is expressed by human monocytes and upregulates the production of GM-CSF via p38 MAPK. $\mathrm{J}$ Immunol 2011, 186:592-601.

14. Amor S, Puentes F, Baker D, van der Valk P: Inflammation in neurodegenerative diseases. Immunology 2010, 129:154-169.

15. Gieseler R, Heise D, Soruri A, Schwartz P, Peters JH: In-vitro differentiation of mature dendritic cells from human blood monocytes. Development Immunol 1998, 6:25-39.

16. Werz O, Klemm J, Radmark O, Samuelsson B: p38 MAP kinase mediates stress-induced leukotriene synthesis in a human B-lymphocyte cell line. J Leukoc Biol 2001, 70:830-838.

17. Rose K, Finger IE, Ferenz KB: Interaction of clodornate with fibroblast growth factor 2 reduces FGF2-activity in endothelial cells. Biomed Pharmacother 2011, 65:46-51.

18. Chomarat P, Banchereau J, Davoust J, Palucka AK: IL-6 switches the differentiation of monocytes from dendritic cells to macrophages Nat Immunol 2000, 1:510-514.

19. Netea MG, Lewis EC, Azam T, Joosten LAB, Jaekal J, Bae S-Y, Dinarello CA, Kim S-H: Interleukin-32 induces the differentiation of monocytes into macrophage-like cells. Proc Natl Acad Sci 2008, 105:3515-3520.

20. Krutzik SR, TAn B, Li H, Ochoa MT, Liu PT, Sharfstein SE, Graeber TG, Sieling PA Liu Y-J, Rea TH, et al: TLR activation triggers the rapid differentiation of monocytes into macrophages and dendritic cells. Nat Med 2005, 11:653-660.

21. Lo AS, Gorak-Stolinska P, Bachy V, Ibrahim MA, Kemeny DM, Maher J: Modulation of dendritic cell differentiation by colony-stimulating factor1: role of phosphatidylinositol 3'-kinase and delayed caspase activation. J Leukoc Biol 2007, 82:1446-1454.

22. Hsu HY, Wen MH: Lipopolysaccharide-mediated reactive oxygen species and signal transduction in the regulation of Interleukin-1 gene expression. J Biol Chem 2002, 277:22131-22139.

23. Nobeli I, Favia AD, Thornton JM: Protein promiscuity and its implications for biotechnology. Nature Biotech 2009, 27:157-167.

24. Franco OL: Peptide promiscuity: an evolutionary concept for plant defense. FEBS Lett 2011, 585:995-1000.

25. Rijnkels M: Multispecies comparison of the casein gene loci and evolution of casein gene family. J Mammary Gland Biol Neoplasia 2002, 7:327-345

26. Carrotta $R$, Canale C, Diaspro A, Trapani A, San Biagio PL, Bulone D: Inhibiting effect of alpha(S)1-casein on A beta(1-40) fibrillogenesis. Biochim Biophys Acta 1820, 2012:124-132.
27. Calder PC, Krauss-Etschmann S, de Jong EC, Dupont C, Frick J-S, Frokiaer $\mathrm{H}_{\text {, }}$ Heinrich J, Garn H, Koletzko S, Lack G, et al: Early nutrition and immunity progress and perspectives. Br J Nutr 2006, 96:774-790.

28. Petermann K, Vordenbäumen S, Maas R, Braukmann A, Bleck E, Saenger T, Schneider M, Jose J: Autoantibodies to alpha(S)1-casein are induced by breast-feeding. PLoS One 2012, 7:e32716.

29. Barbouche R, Forveille M, Fischer A, Avrameas S, Durandy A: Spontaneous IgM autoantibody production in vitro by lymphocytes of normal human neonates. Scand J Immunol 1992, 35:659-667.

30. Kjeldsen F, Savitski MM, Nielsen ML, Shi L, Zubarev RA: On studying protein phosphorylation patterns using bottom-up LC-MS/MS: the case of human (alpha)-casein. Analyst 2007, 132:768-776.

31. Sallusto F, Lanzavecchia A: Efficient presentation of soluble antigen by cultured human dendritic cells is maintained by granulocyte/macrophage colony-stimulating factor plus interleukin 4 and downregulated by tumor necrosis factor alpha. J Exp Med 1994, 179:109-1118.

32. Mebratu $Y$, Tesfaigzi $Y$ : How ERK1/2 activation controls cell proliferation and cell death: is subcellular localization the answer? Cell Cycle 2009 8:1168-1175.

33. Lönnerdal B, Forsum E: Casein content of human milk. Am J Clin Nutr 1985, 41:113-120.

34. Britton JB, Kastin AJ: Biologically active polypeptides in milk. Am J Med Sci 1991, 301:124-132.

doi:10.1186/1471-2172-14-46

Cite this article as: Vordenbäumen et al:: Human casein alpha s1 (CSN1S1) skews in vitro differentiation of monocytes towards macrophages. BMC Immunology 2013 14:46.

\section{Submit your next manuscript to BioMed Central and take full advantage of:}

- Convenient online submission

- Thorough peer review

- No space constraints or color figure charges

- Immediate publication on acceptance

- Inclusion in PubMed, CAS, Scopus and Google Scholar

- Research which is freely available for redistribution 